\title{
A ESCOLA PARA O JOVEM: REPRESENTAÇÕES DE ALUNOS EM SITUAÇÃO DE DISTORÇÃO IDADE-SÉRIE NO MUNICÍPIO DE AREIA BRANCA-RN
}

\author{
A. M. DA SILVA', F. C. S. SOUZA ${ }^{2 *}$ e O. M. MEDEIROS NETA ${ }^{2}$ \\ ${ }^{1}$ Secretaria de Educação do Rio Grande do Norte \\ ${ }^{2}$ Instituto Federal de Educação, Ciência e Tecnologia do Rio Grande de Norte \\ chagas.souza@ifrn.edu.br*
}

Artigo submetido em julho/2015 e aceito em julho/2015

DOI: 10.15628/holos.2015.3183

\section{RESUMO}

Este estudo visa analisar como jovens em situação de distorção idade-série e de vulnerabilidade social, alunos de uma escola pública, situada no município de Areia Branca-RN, percebem a instituição escolar em que estão inseridos. Foi adotada a abordagem da Teoria das Representações Sociais (TRS) para a fundamentação teórica. Foram selecionados oito alunos do 4을 ano do Ensino Fundamental, com a idade entre 11 e 13 anos. A metodologia constou de entrevistas, da aplicação da
Técnica de Associação Livre de Palavras (TALP) e da elaboração de desenhos pelos alunos. Foi notado que, apesar de todas as dificuldades, os alunos pesquisados têm a escola como um elemento de transformação e a representam como um elemento fundamental para se desenvolver como pessoa. Também foi observado que diante de tantos desencontros esses jovens ainda projetam um futuro cheio de sonhos e desejos.

PALAVRAS-CHAVE: Representações sociais, distorção idade-série, vulnerabilidade social.

\section{SCHOOL FOR YOUNG: STUDENTS REPRESENTATIONS OF AGE-SERIES DISTORTION SITUATION IN AREIA BRANCA CITY-RN}

\begin{abstract}
This study aims to examine how adolescents in age-grade and social vulnerability, students of a public school in the municipality of Areia Branca-RN, realize the educational institution where they live. The approach of the Social Representation Theory (SRT) for the theoretical foundation was adopted. Eight students from the 4th grade of elementary school were selected with age between 11 and 13 years. The methodology consisted of
\end{abstract}

interviews, the application of Free Association of Technical Words (TALP) and the production of drawings by students. It was noted that, despite all the difficulties, the students have researched the school as an element of transformation and represent it as a fundamental element to develop as a person. It was also observed that before so many disagreements these young people still design a future full of dreams and desires.

KEYWORDS: Social representations, age-grade, social vulnerability. 


\section{INTRODUÇÃO}

A escola e os seus sujeitos têm relações de afetividade que implicam nas representações dos professores e alunos, bem como de outros sujeitos, sobre o espaço escolar, o processo de ensino e aprendizagem e as sociabilidades daí decorrentes. Essas relações e representações são históricas e inquietam pesquisadores das mais distintas áreas.

No início do século XXI nos indagamos sobre: que escola é essa? Qual a relação entre os alunos, os professores e a escola? A escola é um espaço atrativos para os jovens? De conformidade com essas inquietações é que nos deparamos com o cotidiano de turmas do Ensino Fundamental da Escola Estadual Professora Antônia Girlande, no município de Areia Branca-RN. Em especial, atentamos para uma turma de $4^{\circ}$ ano, muito indisciplinada, onde havia um grande número de alunos repetentes que não sabiam ler nem escrever, totalmente desestimulados e vistos como "os piores" alunos da escola. Assim, voltamos as indagações iniciais, objetivando investigar o sentido que tem a escola para esses alunos e de quais representações sociais se configura aquele espaço para os mesmos.

Nesse sentido, a questão a ser investigada e que norteará este trabalho é: que representações sociais sobre a escola têm os alunos do 40 ano da Escola Estadual Professora Antônia Girlande e que estão em situação de distorção idade-série? Para tanto, optamos pela abordagem da Teoria das Representações Sociais (TRS) para fundamentar teoricamente este trabalho - essa Teoria, como aporte de análise das formações de condutas, possibilita refletir criticamente sobre a influência das representações nas ações dos sujeitos.

A metodologia escolhida para tratar dessa temática foi a entrevista aberta com um grupo de 8 (oito) alunos em atraso escolar do 4ㅇa ano da Escola Estadual Professora Antônia Girlande. A escolha dos integrantes se deu pelo critério de que todos estivessem em atraso escolar na situação de distorção-idade. As entrevistas aconteceram em quatro encontros que serão descritos mais adiante, sendo que no quarto e último encontro foi aplicada a Técnica de Associação Livre de Palavras (TALP), por entendermos que esta técnica permitiria que os alunos expressassem livremente as suas ideias e, com isso, possibilitaria chegarmos o mais próximo possível do que eles pensam enquanto sujeitos.

Os dados foram trabalhados a partir da análise de conteúdo, a fim de uma compreensão mais rica das respostas obtidas, proporcionando assim uma reflexão sobre os resultados. Também utilizei - para facilitar a exposição das ideias dos alunos - a aplicação de desenhos, pois os alunos não sabiam ler nem escrever, além de serem fechados para falar de si mesmos.

Sendo assim, esse artigo está dividido da seguinte maneira: na primeira parte, "Como tudo começou", foi exposto como surgiu a ideia desse estudo e foi justificada a importância do mesmo. Na segunda parte, "Enfocando a distorção idade-série na educação do Brasil contemporâneo", trago algumas considerações importantes sobre esse grave problema presente na educação brasileira e em âmbito local (Areia Branca-RN). Na terceira e última parte, "Para que serve a escola? Indícios representacionais de alunos com distorção idade-série" tratarei das análises dos dados que obtive nos quatro encontros. 


\section{COMO TUDO COMEÇOU}

O que pensamos sobre a escola e seus sujeitos implica em representações, não neutras. Foi com esse entendimento que, em 2014, em visita a Escola Estadual Professora Antônia Girlande para atividades de ensino e pesquisa do Curso de Pós-Graduação lato sensu em Educação e Contemporaneidade, do Instituto Federal de Educação, Ciência e Tecnologia do Rio Grande do Norte, Campus Mossoró deparamo-nos com uma sala de aula de 4 을 ano onde os alunos eram totalmente desestimulados, indisciplinados, desacreditados e representados como os piores alunos da instituição e muitos deles diziam serem obrigados a estarem na escola.

Por entendermos que as relações que se estabelecem na escola são permeadas pelo significado dessa instituição na vida dos alunos (SALES; SILVA, 2011) é que procuramos investigar as representações que os integrantes desse estudo têm sobre a escola, pois os caminhos trilhados por eles serão direcionados pelas concepções trazidas por cada um.

As representações sociais construídas por esses jovens estudantes, nesse momento, definirão que sujeitos eles se tornarão, ou seja, as suas representações sociais sobre a escola serão fundamentos para atitudes e comportamentos futuros:

A representação funciona como um sistema de interpretação da realidade que rege as relações dos indivíduos com o seu meio físico e social. Ela vai determinar seus comportamentos e suas práticas. A representação é um guia para ação, ela orienta as ações e as relações sociais. Ela é um sistema de pré-codificação da realidade porque ela determina um conjunto de antecipações e expectativas. (ABRIC, 1998, p. 28)

Por isso, para alicerçarmos teoricamente este trabalho, nós recorremos à Teoria das Representações Sociais (TRS), desenvolvida na década de 1960 por Serge Moscovici. Ela apresenta uma compreensão profunda dos fenômenos sociais, uma vez que permite compreender como os integrantes desse estudo organizam os seus pensamentos, como se compreendem e como essa compreensão interfere em sua realidade (MOSCOVICl, 1978), além de nos oferecer conceitos importantes, pois investiga o modo de pensar do indivíduo acerca de um determinado objeto. Para Moscovici (1978):

Uma representação social é a organização de imagens e linguagem, porque ela realça e simboliza atos e situações que nos são e que nos tornam comuns. [...] ela é compreendida a título de reflexo, na consciência individual ou coletiva, de um projeto, de um feixe de idéias que Ihe são exteriores. A analogia com uma fotografia captada e alojada no cérebro é fascinante; a delicadeza de uma representação é, por conseguinte, comparada ao grau de definição e nitidez ótica de uma imagem. É nesse sentido que nos referimos, freqüentemente, à representação (imagem) do espaço, da cidade, da mulher, da criança, da ciência, do cientista, e assim por diante (p. 25).

É importante esclarecer a dicotomia que existe sobre o termo "representações sociais", uma vez que é comum tratarmos, ao mesmo tempo, "Representações sociais", a teoria e o seu objeto de estudo. Assim, explicam Santos e Andrade (2002, p. 21):

Falar em representações sociais é remeter-se ao conhecimento produzido no senso comum. Porém, não a todo e qualquer conhecimento, mas a uma forma de 
conhecimento compartilhado, articulado que se constitui em uma teoria leiga a respeito de determinados objetos sociais. Por sua vez, falar na Teoria das Representações Sociais é referir-se a um modelo teórico, um conhecimento científico que visa compreender e explicar a construção desse conhecimento leigo do senso comum. Temos, portanto, a Teoria das Representações Sociais que visa compreender os fenômenos das representações sociais.

Em seu cotidiano, as pessoas interagem, conversam, analisam e pensam sobre os mais diferentes assuntos, e suas práticas sociais são orientadas pela visão que cada sujeito tem sobre determinada coisa ou objeto (MOSCOVICl, 1978). Essa visão das coisas e objetos é construída na relação com os grupos dos quais participam e permite que os indivíduos justifiquem as suas ações. Por serem construídas coletivamente, elas são chamadas de representações sociais, que passam a influenciar as suas relações e comportamentos no mundo.

Segundo Nóbrega (2001),

As representações sociais são elaboradas no âmbito dos fenômenos comunicacionais que repercutem sobre as interações e mudanças sociais. A comunicação social é responsável pelo modo como se forjam as representações sociais. Portanto, as representações sociais são saberes do senso comum construídos nas relações entre os indivíduos. São fenômenos capazes de explicar o modo pelo qual o novo é agregado nos processos de interações sociais, são processos cognitivos que transformam o estranho em algo familiar em um grupo social e enquanto orientadora de condutas, podem funcionar como obstáculos ou facilitadores simbólicos à incorporação de novos conteúdos e práticas propostas pelos processos formativos (p. 64).

Jodelet (2001) define as representações sociais como:

Uma forma de conhecimento, socialmente elaborada e partilhada, com um objetivo prático, e que contribui para a construção de uma realidade comum a um conjunto social. Igualmente designado como saber de senso comum ou ainda, saber ingênuo, natural, essa forma de conhecimento é diferenciada entre outras do conhecimento cientifico. Entretanto é tido como um objeto de estudo tão legítimo quanto este devido à sua importância na vida social e à elucidação possibilitadora do processo cognitivo e das interações sociais (p. 22).

A abordagem da TRS se configura como um elemento importante a ser considerado na análise de questões relativas à compreensão e a evolução da mentalidade sobre atitudes e opiniões e formas de organizações grupais. Para Moscovici (1978, p. 28) “[...] a representação social é um corpus organizado de conhecimento e uma das atividades psíquicas graças às quais os homens tornam inteligível a realidade física e social". Nesse sentido, Dantas (2006) explica que:

A Teoria das Representações Sociais enquanto instrumento de análise do contexto da formação, traz contribuições significativas para a compreensão da construção e da consolidação dos conceitos compartilhados pelos sujeitos pertencentes aquele grupo [...]. Desse modo, as representações sociais oferecem possibilidades de estudos das percepções, conceitos que refletem e orientam pensamentos, opiniões e ações no contexto escolar. Portanto essa teoria permite investigar como os alunos [...] através das interações sociais assimilam, veiculam e também constroem seus próprios conceitos e imagens (p. 38). 
Nesta pesquisa, a TRS como instrumento de análise das formações de condutas, possibilita refletir criticamente sobre a influência da escola na conduta dos educandos. Ou seja, nos permite entender como os alunos compreendem a escola e como essa compreensão influencia na maneira de agir tanto na sala de aula quanto fora dela.

\section{ENFOCANDO A DISTORÇÃO IDADE-SÉRIE NA EDUCAÇÃO BRASILEIRA}

O sistema educacional de um país está diretamente ligado ao seu desenvolvimento, pois a educação escolar é um dos principais meios de produção de novos conhecimentos e de conquista da cidadania. A partir dela, a democracia é consolidada e os ensinamentos necessários à sobrevivência individual e coletiva são disseminados (ANUÁRIO..., 2014; SOUSA, 2001).

Dessa forma, dentre várias instituições, é a escola que tem o papel de proporcionar a apropriação do saber sistematizado. É dela a responsabilidade de propiciar amplas condições e oportunidades de aprendizagem, como afirma a atual Lei de Diretrizes e Bases da Educação Nacional (BRASIL, 2003). Podemos destacar o papel do professor como um mediador, um facilitador dessa aprendizagem, do qual se exige domínio do conhecimento científico e de métodos e técnicas que propiciem aos alunos a apropriação desse conhecimento.

Por conseguinte, tendo em vista a importância da educação para a formação cidadã e o desenvolvimento social, cultural e econômico, é de suma importância o estudo do fenômeno da distorção idade-série, uma vez que ele causa impactos consideráveis sobre os índices do sistema educacional do nosso país.

Conforme os dados preliminares do Censo Escolar de 2013, divulgado pelo Instituto Nacional de Estudos e Pesquisas Educacionais Anísio Teixeira (INEP), existem 40.366.236 matrículas efetuadas no ensino regular em todo Brasil. Destas, 24.225.452 estão concentradas no Ensino Fundamental (BRASIL, 2013).

O Ensino Fundamental é uma fase de grande importância, pois é o alicerce, a base, e tem como papel a formação básica do cidadão; assim, é a única etapa obrigatória e garantida por lei. A LBD (Lei no 9.394/96) diz no seu artigo 4ㅇq que o Ensino Fundamental deve ser obrigatório e gratuito, inclusive para os que não tiveram acesso na idade própria (BRASIL, 1996).

O Brasil possui hoje um rico banco de informações sobre a educação. Periodicamente são divulgados os resultados de avaliações que são aplicadas frequentemente por níveis de ensino e geram dados estatísticos que nos permitem formar uma visão detalhada do sistema educacional brasileiro. No Ensino Fundamental essas avaliações são aplicadas por meio do Sistema de Avaliação do Ensino Básico (SAEB).

O SAEB é composto pela Avaliação Nacional da Educação Básica (ANEB), pela Avaliação Nacional do Rendimento Escolar (ANRESC) e pela Avaliação Nacional de Alfabetização (ANA). A ANA avalia o nível de leitura, escrita e matemática de estudantes matriculados no 30 ano do ensino fundamental em escolas públicas; a ANRESC, também conhecida como Prova Brasil, avalia os conhecimentos nas disciplinas de Língua Portuguesa e Matemática de alunos do 5ㅇ e 9ㅇ das escolas públicas; a ANEB consiste de provas de leitura e Matemática que são aplicadas a estudantes de 50 e 9o anos do Ensino Fundamental e de 3 ano do Ensino Médio das redes pública e privada. Infelizmente, os resultados dessas avaliações não têm sido satisfatórios. 
A prova $A B C$, instrumento de avaliação do Pacto Nacional de Alfabetização na Idade Certa (PNAIC), aplicada em 2012 com alunos do $3^{\circ}$ ano de todas as regiões do país com objetivo de avaliar o nível de alfabetização alcançado pelas crianças em Língua Portuguesa e em Matemática, apontou que na Região Nordeste apenas 30,7\% dos alunos identificam o tema de um texto, assim como seus personagens, e estabelecem relações de causa e consequência entre as informações contidas no enredo, e 18,1\% efetuam adição e subtração de números naturais com diferentes quantidades de algarismos (ANUÁRIO..., 2014).

Isto indica que são muitas as crianças que concluem os anos iniciais do Ensino Fundamental sem estarem plenamente alfabetizadas, considerando que no período de 10 ao $4 \div$ ano elas são avançadas automaticamente, chegando ao final dos anos iniciais deficientes quanto ao que se espera delas. O caso dos integrantes dessa pesquisa é um exemplo, pois estão no 4 o ano e não sabem ler nem escrever. Isso vem afetando consideravelmente o andamento das atividades na sala de aula, de modo que fica difícil avançar com o conteúdo desejado para a série em que se encontram.

De acordo com o Anuário Brasileiro de Educação Básica 2014, a educação no Brasil é marcada pela desigualdade. Os números apresentados por esse documento demonstram que há uma grande diferença quando se comparam alunos ricos e pobres, brancos e negros, alunos do campo e da cidade:

Na Educação Infantil, por exemplo, $44 \%$ das crianças de 0 a 3 anos estão em Creches, no quartil mais rico da população, contra apenas $16,2 \%$ das crianças das famílias mais pobres. A desproporção se repete quando se consideram as crianças de 4 e 5 anos matriculadas na Pré-Escola, definida por lei como obrigatória a partir de 2016: $94,6 \%$ das crianças da população situada entre os $25 \%$ mais ricos estão na escola, contra 77,6\% das mais pobres (ANUÁRIO..., 2014, p. 10).

[...] na faixa etária de 6 a 14 anos, 4,2\% das crianças e adolescentes negros e 17\% dos indígenas estão fora da escola. Entre a população branca da mesma faixa etária, 2,6\% se encontram excluídas das salas de aula. Enquanto na Região Sul $2,5 \%$ das crianças e dos adolescentes de 6 a 14 anos estão fora da escola, nas regiões Norte e Nordeste, os números ficam em $6,1 \%$ e 3,3\%, respectivamente. (ANUÁRIO..., 2014, p. 39).

O gráfico 1 apresenta o Índice de Desenvolvimento da Educação Básica (IDEB) do ano de 2011, por região brasileira. As regiões com maior índice são Sudeste e Sul, com 5,4. O Nordeste é a região com o menor índice: $4,0 \%$.

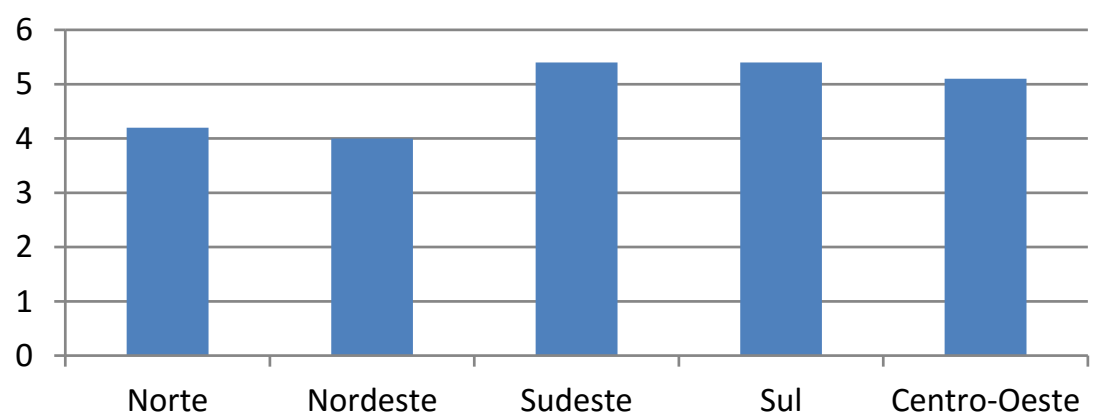

Gráfico 1: Índice de desenvolvimento da educação básica (IDEB) por Região/2011 Fonte: ANUÁRIO..., 2014, p. 60. 
No Brasil, as taxas de reprovação ainda são muito elevadas, atingindo 9,1\% dos alunos de Ensino Fundamental e 12,2\% do Ensino Médio (ANUÁRIO..., 2014). Dos alunos que ingressam na etapa básica da educação na Região Nordeste, apenas 56,9\% conclui o Ensino Fundamental, no Norte esse número é menor, 51,6\% (Ibid.).

Também conforme o Anuário Brasileiro de Educação Básica 2014, o percentual de crianças de 3 o ano que atingem o mais alto nível de proficiência no Nordeste é quase a metade do verificado no Sudeste do País. Grande parcela desses jovens permanece neste nível de ensino devido às deficiências de aprendizado, agravando o problema da distorção idade-série e a defasagem escolar.

No ano de 2004, o Ensino Fundamental teve sua ampliação de oito para nove anos através do projeto de Lei no 3.675/04 que, posteriormente, foi transformado na Lei Ordinária 11274/2006, a qual determina a matrícula obrigatória no Ensino Fundamental aos seis anos. Com essa mudança, a resolução CNE/CEB no 3/2005 estabelece a nova nomenclatura com as seguintes faixas etárias: Ensino Fundamental com pelo menos 9 (nove) anos de duração e até os 14 (quatorze) anos de idade, sendo os Anos Iniciais, com 5 (cinco) anos de duração para crianças de 6 (seis) a 10 (dez) anos de idade, e os Anos Finais com duração de 4 (quatro) anos, para os (pré)adolescentes de 11 (onze) a 14 (quatorze) anos de idade (BRASIL, 2005).

Desse modo, no Brasil, toda criança aos 6 anos deve ingressar no Ensino Fundamental e concluí-lo aos 14 anos, se o estudante cursar toda essa etapa sem interrupções. Aos 15 anos, está previsto que o jovem deve estar matriculado no Ensino Médio e finalizá-lo até os 17. Quando o aluno não acompanha esse ritmo diz-se que ele fica "atrasado" nos estudos e é encaixado nessa situação de distorção ou defasagem idade-série.

A defasagem idade-série, ou distorção idade-série, é a condição em que se encontra o aluno cursando uma série com idade superior a que seria recomendada ou prevista (SARAIVA, 2010). Essa distorção é calculada em anos e representa a diferença entre a idade do aluno e a idade recomendada para a série que ele está cursando. Se a diferença entre a idade do aluno e a prevista para a série é de dois anos ou mais esse aluno encontra-se fora de faixa ou em situação de distorção ou defasagem idade-série. Portanto, no caso dos alunos que compõem a pesquisa que realizei, por estarem na faixa dos doze e treze anos e ainda cursarem o 4음 ano, eles estão nessa situação de atraso há mais de dois anos, de acordo com esse indicador.

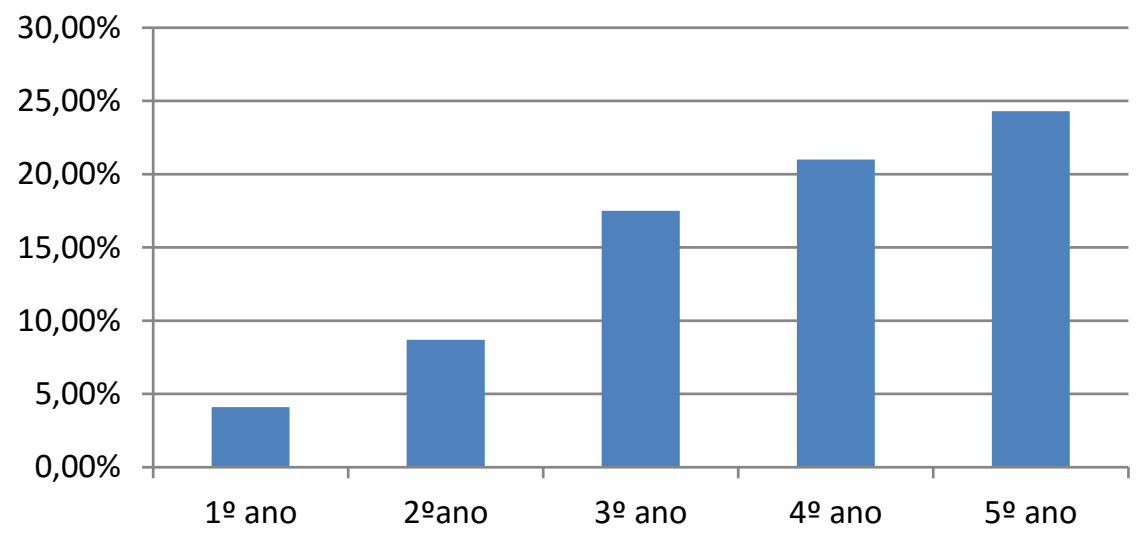

Gráfico 2: Taxa distorção idade-série no Brasil por ano (2013)

Fonte: BRASIL, INEP, 2013. Disponível em: <http://portal.inep.gov.br/indicadores-educacionais> Acesso em: 03 jun. 2014. 
A taxa de distorção idade-série se intensifica no 4ำ e 5ㅇan ano do Ensino Fundamental (gráfico 2). Acreditamos que isso se deve ao fato que, como dito anteriormente, no período do 10 ao 40 ano, o aluno é automaticamente avançado para a série seguinte, chegando ao 4ㅇ e 5ㅇa anos com grandes dificuldades de leitura e escrita. Outro grande problema intensificador desse fenômeno são as elevadas taxas de abandono escolar levando esses alunos a repetirem de ano.

Com relação à taxa da distorção idade-série por regiões, percebe-se uma enorme disparidade entre a Região Nordeste e as demais regiões do país (gráfico 3). O Nordeste apresenta-se com o pior índice: $28,9 \%$. O Sudeste que apresenta a menor porcentagem: 9,2\%.

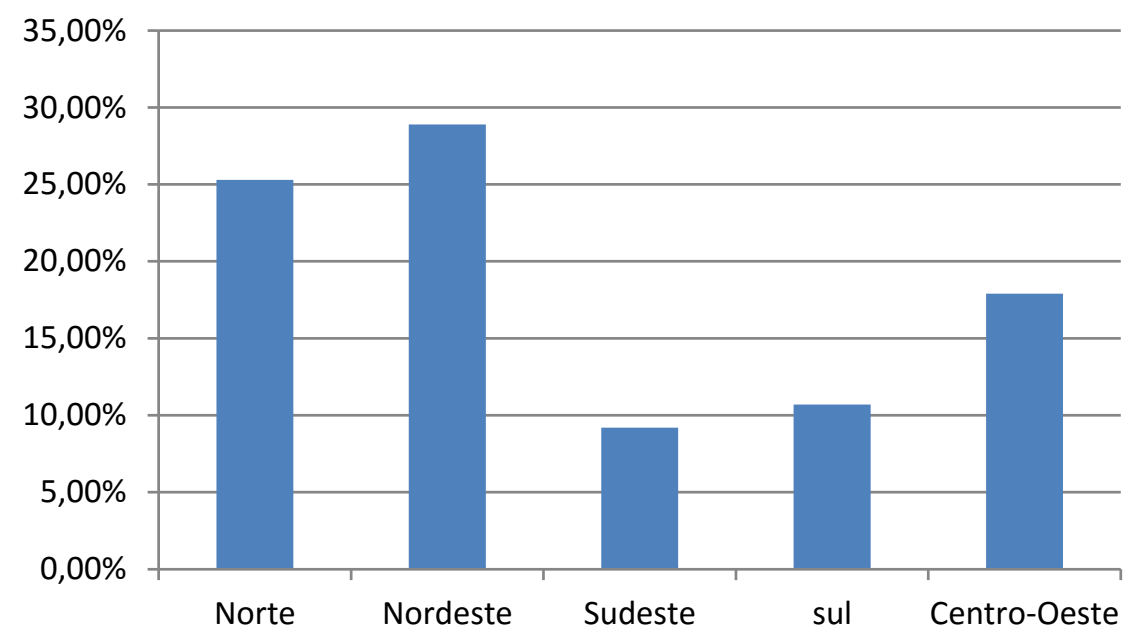

Gráfico 3: Taxa distorção idade-série por regiões (10 ao 50 ano - 2013)

Fonte: BRASIL, INEP, 2013. Disponível em: <http://portal.inep.gov.br/indicadores-educacionais> Acesso em: 03 jun. 2014.

No âmbito da Região Nordeste, o estado do Ceará apresenta-se com a menor taxa de distorção idade-série com 15,5\%, seguido do Maranhão com 18,8\%, e do Pernambuco com 19,7\%. O Rio Grande do Norte apresenta-se com 19,9\%. O estado do Sergipe tem o pior índice, 27,1\%, e a Bahia vem um pouco abaixo do Sergipe com $26,6 \%$.

Como podemos perceber, os números da desigualdade são muito elevados e os mais vulneráveis indicadores sociais do Brasil estão no Norte e Nordeste. Isso acarreta várias consequências que colaboram para uma sociedade extremamente desigual. Diante desse cenário, tornam-se necessárias medidas urgentes por parte dos governantes e dos profissionais da educação.

\section{PARA QUE SERVE A ESCOLA? INDÍCIOS REPRESENTACIONAIS DE ALUNOS COM DISTORÇÃO IDADE-SÉRIE}

Apresentados os índices da distorção idade-série em escala nacional, agora considerei o contexto onde foi realizada a pesquisa apresentada neste artigo, a Escola Estadual Professora Antônia Girlande, no município de Areia Branca-RN.

A Escola Estadual Professora Antônia Girlande foi fundada em 1986 e está situada no bairro Cohab, na periferia do município de Areia Branca e atende uma clientela de baixa renda. É uma escola de pequeno porte e funciona nos turnos matutino e vespertino com a oferta para o Ensino Fundamental I (do 1으 ao 5 ano). A escola conta hoje com 153 alunos matriculados e tem sete 
professores no seu quadro. Possui em sua estrutura física uma pequena área coberta, quatro salas de aula, dois banheiros para os alunos e um para professores e funcionários, uma sala grande onde funciona improvisadamente a direção, a secretaria, a sala de informática e de leitura, além de uma cozinha. Possui também uma grande área aberta que os alunos utilizam como quadra.

Nessa escola, os dados do Censo Escolar 2013 apontam uma taxa de distorção idade-série de 14,4\%, do 10 ao 5ㅇano, um número um pouco menor que a taxa nacional que é de $15,4 \%$ (INEP, 2013). Como vimos anteriormente, em nível nacional, a taxa de distorção se intensifica nos 4 ㅇ e 5 은 anos. No caso da escola em questão, a situação não é diferente, pois ali também encontramos um número muito alto de alunos nessa condição nos 4ํ e 5a anos, conforme podemos ver no gráfico 4.

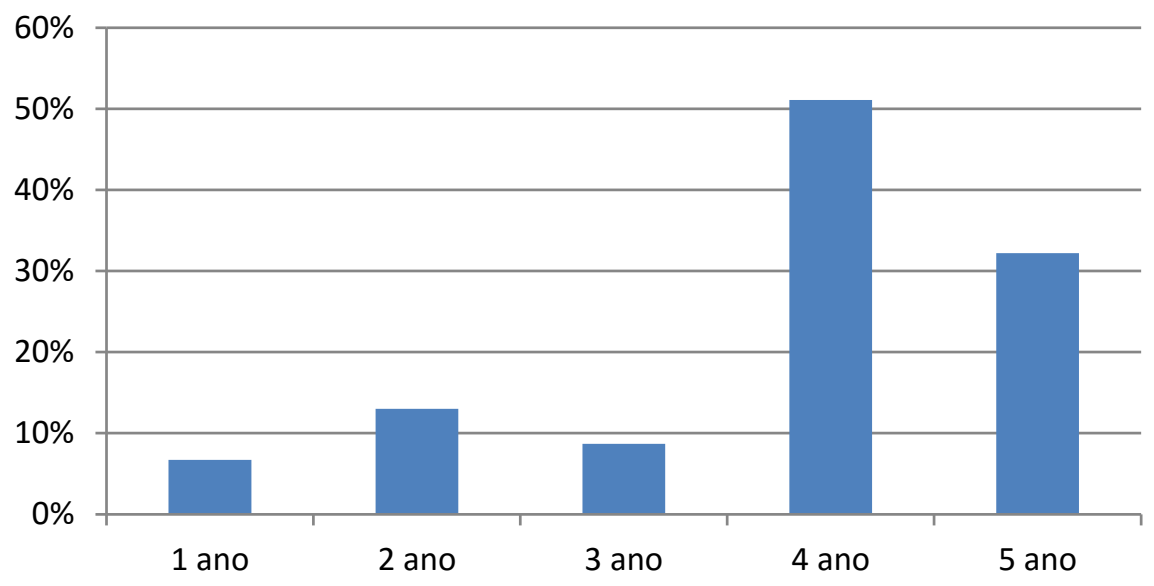

Gráfico 4 - Taxa de distorção idade-série na E. E. Profa Antônia Girlande/ 2013

Fonte: BRASIL, INEP, 2013. Disponível em: <http://portal.inep.gov.br/indicadores-educacionais> Acesso em: 03 jun. 2014.

Como já informei, a pesquisa desenvolvida nessa escola envolveu 8 (oito) alunos que estão em situação de distorção idade-série. Mas, antes de apresentar os resultados dessa investigação, faz-se necessário tecer algumas considerações sobre esses discentes, pois devemos levar em consideração que, para entendermos as suas dificuldades, temos que conhecer um pouco do contexto em que eles vivem. Para Lima (2009, p. 9), “[...] toda criança tem sua história de vida, a qual deve ser conhecida pelos educadores que atuam diretamente com ela, podendo assim compreender melhor seus alunos e traçar estratégias eficazes para superar possíveis problemas".

Os integrantes da pesquisa vivem em um bairro de periferia de Areia Branca onde o índice de violência é bastante elevado por existirem vários pontos de venda e uso de drogas. Em algumas famílias são comuns os casos de problemas envolvendo o seu uso. Por exemplo, é o caso do aluno Caio, que teve a mãe detida por envolvimento com entorpecentes. Também há casos de problemas de interação familiar como o do aluno João que enfrenta dificuldades de relacionamento com o novo companheiro da mãe. Além disso, a extrema situação de pobreza em que a maioria vive, coloca alguns em situações difíceis como a do aluno José, que fica em casa sozinho, praticamente o dia todo, pois os pais trabalham fora. A situação difícil leva também a aluna Ana a trabalhar fora de casa para ajudar na renda familiar.

Alguns discentes da escola vão para a aula sem comer, com uniformes sujos e até rasgados. Não frequentam com assiduidade às aulas e, muitas vezes, vão sem material escolar, recorrendo à direção à procura de lápis e caderno para realizarem as tarefas. Os pais não parecem demonstrar 
interesse pela vida escolar desses alunos, visto que raramente frequentam a escola nem comparecem aos eventos realizados como as reuniões de pais e mestres. Possivelmente, a falta de tempo e de clareza em relação a importância dessas atividades sejam as razões para isso.

As relações e as vivências desses alunos no ambiente familiar exercem um papel importante para a formação da sua personalidade e do seu caráter. O Artigo 19 do Estatuto da Criança e do Adolescente determina que a família é responsável por criar, cuidar, educar, proteger e garantir o desenvolvimento de suas crianças (BRASIL, 1990).

Sobre a importância da família na formação do sujeito, Moreno (2001, p. 253) ressalta que o ser humano é um ser sensível e precisa de carinho, respeito, estimulo. Nos pais, a criança precisa encontrar o primeiro exemplo vivo dos grandes traços de caráter que devem inspirar sua conduta individual e comunitária; a família é sua escola viva de virtudes.

Após caracterizar o contexto social e familiar dos estudantes integrantes desta pesquisa, passamos para a descrição dos procedimentos utilizados para a concretização deste estudo.

Como dito no início deste trabalho, a metodologia utilizada constou de entrevistas abertas que aconteceram em quatro encontros. Em três deles, os estudantes foram indagados sobre a família, a escola e sobre eles mesmos. A decisão de utilizar essa metodologia deve-se ao fato de que trabalhar "[...] com narrativas na pesquisa e/ou no ensino é partir para a desconstrução/construção das próprias experiências tanto do professor/pesquisador como dos sujeitos da pesquisa e/ou do ensino" e exige que a relação dialógica se instale criando uma cumplicidade de dupla descoberta. Pois, ao mesmo tempo que se descobre no outro, os fenômenos revelam-se em nós. (CUNHA, 1997, p. 3, grifo nosso).

O trabalho de reflexão, a partir da narrativa dos sujeitos, nos deu possibilidades de aproximar-nos da subjetividade de cada um. De acordo com Josso (2007), as narrativas são significativas visto que:

Permite estabelecer a medida das mutações sociais e culturais nas vidas singulares
e relacioná-las com a evolução dos contextos de vida profissional e social. As
subjetividades exprimidas são confrontadas à sua frequente inadequação a uma
compreensão liberadora de criatividade em nossos contextos em mutação. O
trabalho sobre essa subjetividade singular e plural torna-se uma das prioridades
da formação em geral e do trabalho de narração das histórias de vida em
particular (p. 415).

Recorremos também a Técnica de Associação Livre de Palavras (TALP). É uma técnica projetiva advinda da psicologia que se utiliza de estímulos para evidenciar universos semânticos que colocam em evidencia os universos comuns de palavras a fim de obter respostas que nos possibilite chegar o mais próximo possível do que os sujeitos estão pensando (NOBREGA; COUTINHO, 2003).

Segundo Nóbrega e Coutinho (2003), os pesquisadores em Representação Social (RS) visam identificar as dimensões latentes nas RS, através das configurações dos elementos que constituem a trama ou redes associativas dos conteúdos evocados em relação a cada estimulo indutor. Portanto, 
Trata-se de uma técnica projetiva orientada pela hipótese de que a estrutura psicológica do sujeito torna-se palpável através das manifestações de condutas de reações, evocações, escolhas e criação, constituindo-se em índices reveladores do conjunto da personalidade. Enquanto técnica projetiva deveria atuar sobre a estrutura psicológica do sujeito tornando-a evidente (NÓBREGA, COUTINHO, 2003, p. 67).

Outro recurso utilizado para obtenção dos resultados foi a aplicação de desenhos, uma vez que os estudantes não sabiam ler nem escrever e tinham dificuldades para falar de si mesmos. Para Natividade, Coutinho e Zanella (2008), as crianças utilizam várias formas de se comunicarem, tais como gestos, signos, imagens e até mesmo o silêncio, diferentemente do adulto no qual a forma verbal predomina, fazendo-se necessário a utilização deste recurso.

Após o consentimento da direção para desenvolver a pesquisa, foi elaborado um termo de consentimento para que os pais autorizassem a participação de seus filhos, visto que se tratava de menores de idade. Vale ressaltar que foi muito difícil contatar essas pessoas, pois os pais e responsáveis por esses alunos não vão à escola com frequência. Por isso, na maioria dos casos, foi necessário ir à residência dos alunos para que os pais ou responsáveis assinassem a autorização da entrevista. Em tais oportunidades, os objetivos da pesquisa lhes foram devidamente esclarecidos e eles responderam de forma positiva sem impor nenhum obstáculo.

Primeiramente, é relevante frisar que tivemos dificuldades de reunir os estudantes, pois eles, como mencionado, faltam muito às aulas. Foram marcados dois encontros em horários diferentes e nenhum aluno compareceu, uma vez que o único horário acessível era ao final das aulas. Os contatos foram rápidos e marcados pelo pouco interesse dos integrantes: falavam pouco e estavam sempre apressados.

O primeiro encontro efetivo teve a participação de cinco alunos. O principal propósito desse encontro foi para que os estudantes conhecessem os objetivos da pesquisa, falassem sobre si mesmos e quais as suas expectativas quanto ao futuro. Tive a preocupação de deixar claro para o grupo que os nossos encontros tinham o objetivo de auxiliá-los no sentido de tentar entender porque que eles não conseguiam avançar de ano. Também deixei claro que eles podiam expressarse livremente. Assim, após me apresentarmos, pedi para que cada um fizesse o mesmo, dissessem o nome e a idade, o que cada um queria ser no futuro e o que eles teriam que fazer para alcançarem esse objetivo.

Percebemos, nesse encontro, através dos discursos dos alunos, que eles entendem o papel da escola e a importância desta para a aquisição de conhecimentos como um aspecto fundamental para se desenvolverem como pessoa. Isso ficou evidente quando perguntei sobre o que cada um queria ser no futuro e o que eles teriam que fazer pra alcançarem esse objetivo: "Tenho que estudar muito, aprender a ler, escrever..." (JOÃO); "Aprender a ler e escrever, ser uma pessoa boa... (PEDRO); "Tem que ganhar dinheiro, estudar muito, pra ser alguém na vida, porque... sabe, porque, nessa vida, não tenho nada..." (JOSÉ); "Também tem que saber ler e escrever bem..." (ANA).

Ainda nesse encontro, explorando as falas, foi percebido que, em meio a tantas dificuldades e crises familiares, os participantes da pesquisa ainda idealizaram projetos de vida, viram seu futuro com várias possibilidades e sonhos. Isso ficou evidente quando perguntado o que eles queriam ser no futuro. As respostas foram: advogada, professora, doutor. Contudo, sentem-se 
perdidos, sem orientação nem motivação, com medo do que os espera, mas acreditam que irão conseguir a realização de seus sonhos: "Quero ser alguma coisa na vida..." (JOÃO); "Meu nome é Pedro tenho 12 anos e quero ser doutor" (PEDRO); "É... Quero ser advogada" (MARIA).

Como mencionado anteriormente, nesse primeiro encontro, os alunos não se envolveram como era esperado: riam muito, tinham muita conversa paralela e ficavam com vergonha de falar sobre si. Em vista disso, no segundo encontro, foi adotada a técnica de desenho com o intuito de facilitar a comunicação.

O segundo encontro teve a participação de quatro alunos. Foi solicitado que cada um desenhasse algo que marcou a sua vida e, em seguida, justificasse o motivo de ter feito aquele desenho. Antes da apresentação do desenho foi solicitado que cada um falasse um pouco sobre o seu dia a dia e a sua relação com a família.

Ao analisarmos os relatos do segundo encontro, percebemos que a família se faz muito ausente. No caso dos alunos participantes deste estudo, destaco aqui os diálogos que tive com dois deles:

\section{Diálogo 1:}

Professora: você fica em casa com quem?

João: com minha irmã.

Professora: só com sua irmã?

João: e minha mãe.

Professora: sua mãe faz o que?

João: minha mãe fica fazendo o almoço e depois vai trabalhar.

Professora: ela trabalha em que?

João: trabalha na casa de uma mulher.

Professora: e o seu pai?

João: meu pai trabalha na firma.

Diálogo 2:

Professora: Seu pai e sua mãe trabalham?

José: trabalha sim.

Professora: eles trabalham em que?

José: minha mãe, passa o dia na rua na moto, vai deixar os meninos que ela deixa na escola e depois vai buscar. E meu pai varre as ruas.

Professora: e você fica com quem em casa?

José: vou pra escola e quando eu chego fico sozinho.

Acreditamos que a ausência da família é um grande obstáculo, considerando-se que toda criança precisa de estímulo, proteção e de ajuda familiar. Para Sales e Silva (2011), a família é uma referência para o jovem que, na maioria das vezes, a idealiza.

Com relação aos conteúdos dos desenhos, todos desenharam uma casa. Foi observado que a maioria dos desenhos tinha uma relação direta com algum momento em que a família se fazia mais presente: o aluno João desenhou a casa onde a mãe lhe ensinava as tarefas de casa; o aluno José desenhou a casa da avó que, segundo ele, era onde todos moravam juntos; as alunas Maria e Ana são irmãs e também desenharam uma casa. Ana afirmou que era a antiga casa onde elas moravam e, quando questionada sobre o porquê do desenho, ela respondeu que lá era onde ela mais brincava com os irmãos. 
É sabido que a família é a nossa primeira escola. É nela que aprendemos nossos primeiros ensinamentos. Os pais são os primeiros educadores, aqueles que constroem os alicerces e potencializam os seus interesses (MORENO, 2001). "É na família que se pode vivenciar a primeira fonte de amor e contato de vida, é nela que a criança aprende a se humanizar e a viver intensamente esse sentimento, que os pais transmitem aos filhos" (LIMA, 2009, p. 7).

O artigo 20 da LDB deixa clara que a educação da criança é dever da família e do estado e deve ser inspirada nos princípios de liberdade e nos ideais de solidariedade humana (BRASIL, 2003). Assim, a escola é o espaço que vem após a experiência familiar e deve oferecer amplas condições e oportunidades de aprendizagem (LDB 9394/96). É o ambiente em que o indivíduo assimila o saber sistematizado e estará presente em várias etapas da sua vida.

Tanto a família como a escola, têm papeis importantes no processo de educação e socialização dos alunos. Portanto, não podemos pensar a educação com essas duas esferas separadas. Assim, compreende-se que é fundamental e necessário o elo família-escola em prol do sucesso do desenvolvimento das nossas crianças e adolescentes. Para Sousa (2012), família e escola são os principais suportes com que a criança pode contar para enfrentar desafios, visto que, integradas e atentas, podem detectar dificuldades de aprendizagem que ela possa apresentar, podendo contribuir de maneira eficiente em benefício da mesma.

Constatamos no segundo encontro, que as consequências da desigualdade social afetam diretamente a esses estudantes. As condições precárias de vida os forçam a ter responsabilidades de uma pessoa adulta, tendo até que trabalhar fora fazendo "bicos" para ajudar aos pais. "Esta condição é vista como atividade que compromete o desenvolvimento das crianças e adolescentes, uma vez que as retira de atividades como a escola, o lazer e o convívio com os pares" (SOUSA, 2012, p. 33). Este é o caso da aluna Ana, conforme podemos ver na transcrição do diálogo que tive com ela:

Professora: Ana, eu quero que você fale um pouco de como você é quando você tá casa. Como é a Ana em casa?

Ana: varro casa, lavo banheiro... eu só não ajudo mais porque eu fico lá em [X] ajudo ela...

Professora: você ajuda ela em quê?

Ana: varrer casa, passar pano, faço as coisas...

Professora: ela dá alguma ajuda a você?

Ana: dá.

Professora: dá o quê?

Ana: ela dá cento e oitenta.

Professora: é? Todo dia você vai pra lá e faz isso?

Ana: é.

Professora: então é como se fosse um trabalho, né?

Ana: é.

Além de todos esses percalços, ainda existe o problema da reorganização familiar. É o caso do aluno João, que enfrenta a separação dos pais e convive com um padrasto que, percebemos pela sua fala, parece não gostar muito.

João: minha mãe me ajudava nos deveres, ensinava os deveres...

Professora: isso foi quando? Na época que você brincava aí no desenho ? 
João: é.

Professora: e agora ela não ajuda mais não?

João: não!

Professora: por que antes ela ajudava e agora não ajuda mais?

João: por causa do home [sic] dela.

Professora: e você não mora com ele não?

João: com quem?

Professora: com sua mãe e o marido da sua mãe?

João: moro.

Professora: e por que você acha que ela não quer mais ajudar você?

João: por causa dele.

Professora: mas por que você acha que é por causa dele?

João: porque ele não deixa ela sair... não deixa ela sair pra canto nenhum...

No terceiro encontro, como no anterior, também utilizamos o método do desenho para facilitar a comunicação entre os envolvidos. Esse encontro teve a presença de quatro estudantes. Foi pedido que eles fizessem um desenho sobre a escola, o que eles mais gostavam e o que eles menos gostavam, e depois eles explicassem o desenho feito.

Quando pedimos para que desenhassem a parte que mais gostavam na escola todos desenharam a quadra e disseram que o momento que mais gostavam na escola era o recreio. Isso é perfeitamente justificável, pois estamos tratando com alunos em transição da infância para adolescência e é comum que o brincar seja uma de suas atividades preferidas. Além disso, em casa eles não têm a oportunidade de se divertir, pois alguns se ocupam de atividades domésticas e responsabilidades de adultos. Os dois diálogos abaixo demonstram esses fatos:

\section{Diálogo 1:}

Professora: Por que você desenhou a quadra?

Luiz: porque é o lugar mais legal que eu acho.

Professora: mas por que você acha lá o lugar mais legal da escola?

Luiz: porque nós brinca [sic] lá... na recreação você manda nós ir pra lá, ficar jogando bola lá, também a gente brinca eu, João e José. É bom pra brincar!

\section{Diálogo 2:}

Caio: a parte que eu mais gosto é aqui na escola é o recreio

Professora: por que o recreio?

Caio: porque o recreio é pra brincar e conversar... e aqui eu brinco, em casa eu não brinco, só trabalho...

Professora: em casa você não brinca por que?

Caio: porque tem que ajudar meu pai fazer as coisas. Meu pai chega cansado e tem que ajudar ele...

Professora: ajudar fazer o que?

Caio: tudo: varrer a casa, lavar louça, fazer comida, tudo!

Professora: e a sua mãe não ajuda?

Caio: não.

Professora: Por que ela não ajuda?

Caio: porque ela tá na cadeia. Tá [sic] presa na cadeia, a polícia veio e levou ela presa...

Professora: e faz tempo que ela está lá? 
Caio: foi no ano passado.

Professora: sei... e você sente falta dela?

Caio: (não respondeu)

Professora: você gostaria que ela voltasse pra casa?

Caio: gostaria.

Ao observamos a faixa etária dos alunos que compõem este estudo, nós percebemos que os mesmos se encontram em uma fase delicada que é a de transição da infância para a adolescência. Esse é um período crítico, abala consideravelmente o emocional e é a etapa mais complexa do desenvolvimento do indivíduo (MORENO, 2001).

No caso dos alunos que foram os sujeitos desta pesquisa, essa situação torna-se mais grave, visto que alguns moram em lares desestabilizados e estão em situação de risco social. No caso do aluno Caio, ele é um pré-adolescente e a sua mãe encontra-se no presídio da cidade, de modo que ele precisa ajudar ao pai e ainda se responsabilizar pelos afazeres da casa onde mora.

Quanto ao desenho solicitado acerca daquilo que eles menos gostavam na escola, eles desenharam a secretaria, tendo em vista que é para onde os alunos são destinados quando não se comportam, inclusive os integrantes deste estudo, como se vê no diálogo que tive com os alunos José e Luiz:

José: [...] a parte mais ruim é... eu dentro da secretaria.

Professora: e por que você fez você dentro da secretaria?

José: porque no ano passado eu fui pra lá... e... e eu ia sendo expulso.

Luiz: é na secretaria também...

Professora: e você desenhou na secretaria por quê?

Luiz: porque quando tia Alice tava [sic] operada, aí a outra professora botou eu pra secretaria...

Professora: mas você lembra por que mandaram você ir pra secretaria?

Luiz: por que eu bati num cara.

Professora: mas o que aconteceu que você bateu no colega?

Luiz: ah tia! Sei lá, me esqueci.

Professora: então a parte que você mais gosta é a quadra e a que você menos gosta é a secretaria?

Luiz: é.

No quarto encontro foi aplicado a Técnica de Associação Livre de Palavras (TALP), com a palavra-estímulo "ESCOLA". Nesse momento, contamos com a participação de sete alunos. A técnica foi aplicada da seguinte forma: aos alunos, solicitamos que escrevessem as três primeiras palavras que viessem a sua cabeça ao ouvirem a palavra ESCOLA e depois justificassem o porquê das escolhas dessas palavras.

É importante ressaltar que, como esses alunos não sabiam escrever, eu mesma fazia o registro das palavras que eles diziam e as suas justificativas. A seguir, apresentamos no quadro 1 as palavras obtidas na TALP a partir da palavra estímulo "ESCOLA". 


Quadro 1 - Palavras obtidas com a palavra estímulo - ESCC
\begin{tabular}{|c|c|}
\hline Palavras & Frequência \\
\hline Aluno & 1 \\
\hline Professora & 1 \\
\hline Merenda & 2 \\
\hline Ler & 1 \\
\hline Escrever & 2 \\
\hline Aprender & 3 \\
\hline Livros & 1 \\
\hline Sala & 1 \\
\hline Estudar & 3 \\
\hline Brincar & 2 \\
\hline Tarefa & 1 \\
\hline Obediência & 1 \\
\hline Respeito & 1 \\
\hline
\end{tabular}

Tendo em mãos as palavras obtidas pela TALP, fizemos uma organização em dois campos: o primeiro representa a dimensão pedagógica e traz os elementos que julgamos essenciais ao processo de ensino-aprendizagem; o segundo trata da dimensão afetiva e é constituído das relações e sentimentos envolvidos no ambiente escolar (Quadro 2).

Quadro 2 - Campos dimensionais

\begin{tabular}{|c|c|}
\hline Dimensão pedagógica & Dimensão afetiva \\
\hline $\begin{array}{c}\text { Aluno, ler, escrever, aprender, livros, salas, } \\
\text { estudar, tarefa. }\end{array}$ & $\begin{array}{c}\text { Merenda, brincar, professora, obediência, } \\
\text { respeito. }\end{array}$ \\
\hline
\end{tabular}

Com relação ao campo "Dimensão pedagógica", as palavras mais evocadas pelos alunos foram aprender e estudar. As palavras ler e escrever sempre vêm ligadas a palavra aprender. Foi percebido, no discurso dos estudantes, que a palavra aprender apresenta-se com o sentido muito forte, junto com um desejo de adquirir conhecimento. Isso significa que, para eles, a aquisição do conhecimento é um aspecto fundamental para se desenvolverem como pessoa. Já as palavras livro e sala vêm como elementos vinculados ao processo ensino aprendizagem, como disse uma aluna: "A gente faz as tarefas e escreve nos livros e estuda tudo na sala" (MARIA).

Quanto ao campo "Dimensão afetiva", constituído dos elementos de afetividade e de alguns sentimentos envolvidos no ambiente escolar, ou seja, das relações que estão envolvidas no processo educativo, a professora, na justificativa desses estudantes, aparece como uma figura boa e que merece respeito e obediência: "Porque tem aluno e a minha professora é boa..." (ANA); "Porque tem que respeitar a professora e obedecer ela..." (JOÃO).

A palavra merenda vem ligada ao desejo de saciar a fome. É importante lembrar que muitos alunos saem de casa sem tomar o café da manhã e anseiam pela chegada da hora do recreio com intuito de fazer a sua primeira refeição do dia.

Já a palavra brincar traz o sentido de diversão, haja vista que a escola não é um lugar apenas para fazer lições, mas também um lugar de interação social, o que ficou claro nas palavras dos alunos: "Tava [sic] dizendo que ia bota [sic] um parquinho aí atrás, vão colocar não?" (JOSÉ); "Brinco com meus amigos... e como, quando tô [sic] com fome na hora do recreio" (LUIZ); "Porque o recreio é pra [sic] brincar e conversar... e aqui eu brinco, em casa eu não brinco, só trabalho..." (CAIO). 
As palavras mais evocadas pelos educandos foram aprender e estudar. Explorando as narrativas e relacionando-as com essas duas palavras, verificamos que eles compreendem a aprendizagem e o estudo como um instrumento de transformação e entendem a dimensão pedagógica da escola. Reconhecem a importância da aquisição do conhecimento e julgam a escola como um aspecto fundamental para se desenvolver como pessoa. Ou seja, eles entendem o importante papel da escola e que é através da aprendizagem e do estudo que o indivíduo se desenvolve.

Porém, se as representações sociais sobre a escola são fundamentais para atitudes e comportamentos futuros, como afirmei anteriormente, pode-se considerar que o fato desses alunos estarem "fora de faixa", e até alguns permanecerem assim há anos seguidos, mesmo que eles demonstrem entender o importante papel da escola para a sua formação, isso só pode ser compreendido se levarmos em consideração outros aspectos que apresentam-se como fortes obstáculos para esses alunos e que os forçam, inconscientemente, a viver nessa situação de defasagem e a não avançar junto com os seus colegas. Seriam estes: a situação econômica precária em que vivem, a falta de uma estrutura familiar sólida, a falta de momentos de lazer, o meio social em que estão inseridos, a falta de melhorias na estrutura física da escola pesquisada, a necessidade de uma reforma no sistema escolar de forma que envolva a escola com as questões sociais a sua volta, dentre outras razões.

\section{CONSIDERAÇÕES FINAIS}

O problema da distorção idade-série é consequência de um sistema de intensa desigualdade que afeta a qualidade do nosso ensino e interfere diretamente no direito que nossas crianças e adolescentes têm de aprender.

Nesse contexto, apesar de todas as dificuldades e encalços, esses estudantes compreendem a escola como um elemento de transformação e a julgam como um aspecto fundamental para se desenvolverem como pessoa. Mesmo diante de tantas dificuldades e sob o risco social, esses alunos ainda projetam um futuro cheio de sonhos e desejos.

Percebemos que no decorrer dos encontros houve uma pequena, mas significativa, mudança no comportamento dos alunos que integraram este estudo. Estavam mais empenhados, mais responsáveis nas tarefas, além de apresentarem uma melhor conduta em sala de aula. Atribuímos isso ao fato de se sentirem ouvidos e valorizados com nossas conversas. Por isso, considero imprescindível, enquanto professor, refletirmos sobre a nossa ação docente constantemente, pois é muito enriquecedor para nós problematizarmos a nossa prática. Acredito que, dessa forma, estaremos contribuindo para um ensino de qualidade para nossas crianças.

Diante disso, não podemos desanimar nem cruzar os braços diante dos problemas que enfrentamos na sala de aula. Não podemos deixar os nossos alunos a mercê dos problemas sociais. Precisamos, como educadores, ter um compromisso com nossos educandos e, sempre que possível, desenvolver instrumentos que nos auxiliem a buscar por soluções de problemas que venham a surgir, de modo que eles possam ter a chance de, no futuro, terem seus sonhos realizados.

Entretanto, é fundamental que a escola trabalhe com a conscientização dos pais, no sentido de perceber a importância de seu papel para o bom desenvolvimento do processo 
ensino/aprendizagem de seus filhos. Quando a família trabalha em conjunto com a escola, ambas com o mesmo objetivo, torna-se mais harmônico o trabalho de formação do filho/aluno e, consequentemente, promoverá melhorias no sistema de ensino.

\section{REFERÊNCIAS BIBLIOGRÁFICAS}

1. ABRIC, Jean Claude. A abordagem estrutural das representações sociais. In: MOREIRA, Antonia Silva Paredes; OLIVEIRA, Denise Cristina. (org.). Estudos interdisciplinares de representação social. Trad. Pedro Humberto Faria Campos. Goiânia: Ab editora, 1998, p. 27- 37.

2. ANUÁRIO BRASILEIRO DA EDUCAÇÃO BÁSICA 2014. Todos pela educação/Editora Moderna, 2014. Disponível em: <http://pnld.mLoderna.com.br>. Acesso em: 05 out. 2014.

3. BRASIL. Lei no $\mathbf{8 . 0 6 9}$, de 13 de julho de $\mathbf{1 9 9 0}$. Dispõe sobre o Estatuto da Criança e do Adolescente e dá outras providências. Brasília-DF, 1990. Disponível em: < http://www.planalto.gov.br/ccivil_03/leis//8069.htm> Acesso em: 19 out. 2014.

4. _ Ministério da Educação. Secretaria de Educação Média e Tecnológica. Parâmetros Curriculares Nacionais: bases legais. Brasília-DF, 1999.

5. Lei de Diretrizes e Bases da Educação (Lei 9.394/96). 6. ed. Rio de Janeiro, DP\&A, 2003.

6. Ministério da Educação. Secretaria de Educação Básica. Ensino Fundamental de Nove Anos: orientações gerais. Brasília-DF, 2004.

7.

Parecer CNE/CEB № 18, de 05 de outubro de 2005. Orientações para a matrícula das crianças de 6 (seis) anos de idade no Ensino Fundamental obrigatório, em atendimento à Lei n 11.114, de 16 de maio de 2005, que altera os Arts. 6ㅇ, 32 e 87 da Lei no 9.394/1996. BrasíliaDF, $2005 . \quad$ Disponível em: <http://www.profdomingos.com.br/federal_parecer_cne_ceb_18_2005.pdf>. Acesso em: 06 out. 2014.

8. Censo escolar. Brasília: INEP, 2013. Disponível em < http://portal.inep.gov.br/basicacenso>. Acesso em: 20 out. 2014.

9. _ Indicadores educacionais: educação básica. Brasília: INEP, 2013. Disponível em: <http://portal.inep.gov.br/indicadores-educacionais>. Acesso em: 03 jun. 2014.

10. CUNHA, Maria Isabel da. Conta-me agora! As narrativas como alternativas pedagógicas na pesquisa e no ensino. Revista da Faculdade de Educação. v. 23, n. 1-2, jan./dez. São Paulo, 1997.

11. DANTAS, Lely Sandra Correia. Representações Sociais do ensinar e do aprender pelos alunos do curso de pedagogia da UFRN. Monografia (graduação em Pedagogia). Natal: Universidade Federal do Rio Grande do Norte, 2006.

12. JARDILINO, José Rubens Lima; BARBOSA, Nayara Ferreira de Moura. Formação inicial e estágio: uma reflexão sobre o conceito de "professor-reflexivo". Revista Diálogo Educacional, Paraná, v. 12, n. 37, set./dez., 2012, p. 763-781.

13. JODELET, Denise. Representações Sociais: um domínio em Expansão. In: JODELET, Denise (org.). As Representações Sociais. Trad. Lilian Ulup. Rio de Janeiro: EDUERJ, 2001, 17-44.

14. JOSSO, Marie-Christine. A transformação de si a partir da narração de histórias de vida. Porto 
Alegre/RS. Educação, n. 3, set./dez., 2007, p. 413-438.

15. LIMA, Liliana Correia de. Interação família-escola: papel da família no processo ensino aprendizagem. Curitiba: Secretaria de Educação do Paraná, 2009. Disponível em: <http://www.diaadiaeducacao.pr.gov.br/portals/pde/arquivos/2009-8.pdf>. Acesso em: 28 ago. 2014.

16. MORENO, Viriaco Izquierdo. Educar em valores. Tradução Maria Luiza Garcia Prada. São Paulo: Paulinas, 2001, p. 288.

17. MOSCOVICl, Serge. A Representação Social da Psicanálise. Trad. Álvaro Cabral. Rio de Janeiro: Zahar Editores, 1978.

18. NATIVIDADE, Michelle Regina da; COUTINHO, Maria Chalfin; ZANELLA, Andréa Vieira. Desenho na pesquisa com crianças: análise na perspectiva histórico cultural. Contextos clínicos, v. 1, n. 1, jan. 2008, p. 9-18.

19. NÓBREGA, Sheva Maia. A teoria das Representações Sociais. In: MOREIRA, Antônio Silva Paredes. Representações Sociais: teoria e prática. João Pessoa: Editora Universitária, 2001, p. $55-87$.

20. NÓBREGA, Sheva Maia da; COUTINHO, Maria da Penha de Lima. O teste de Associação Livre de Palavras. In: COUTINHO, Maria da Penha de Lima. Representações sociais: Abordagem interdisciplinar. João Pessoa: Editora Universitária/UFPB, 2003, p. 67-77.

21. SALES, Leila Maria Ferreira; SILVA, Joyce Mary Adam de Paula e. Família e escola interfaces da violência escolar. São Paulo: Cultura Acadêmica, 2011.

22. SANTOS, Carmen Sevilla Gonsalves dos; ANDRADE, Fernando César Bezerra de. Representações sociais e formação do educador revelando interseções do discurso. João Pessoa: Editora Universitária, 2002.

23. SARAIVA, Ana Maria Alves. Distorção idade-série. In: OLIVEIRA, Dalila Andrade; DUARTE, Adriana Maria Cancela; VIEIRA, Lívia Maria Fraga. Dicionário trabalho, profissão e condição docente. Belo Horizonte: UFMG/Faculdade de Educação, 2010. Disponível em: <http://www.gestrado.org/?pg=dicionario-verbetes\&id=237> Acesso em: 02 out. 2014.

24. SOUSA, Jacqueline Pereira de. A importância da família no processo de desenvolvimento da aprendizagem da criança. Trabalho de Conclusão de Curso. Curso de Pós-graduação em Psicopedagogia Clínica e Institucional (Especialização). Departamento de Pró-reitoria de Educação Continuada, Instituto de Estudos Superiores do Ceará, Fortaleza, 2012. Disponível em: <http://www.apeoc.org.br/extra/artigos_cientificos/A_IMPORTANCIA_DA_FAMILIA_NO _PROCESSO_DE_DESENVOLVIMENTO_DA_APRENDIZAGEM_DA_CRIANCA.pdf $>$. Acesso em: 27 ago. 2014.

25. SOUSA, Jesus Maria. As missões (im)possíveis do professor: o bem/mal estar docente. Tribuna da Madeira. Madeira: Universidade da Madeira, 2001, p. 13-16. Disponível em: <http://www3.uma.pt/jesussousa/Tribuna/7.pdf> Acesso em: 03 out. 2014.

26. SOUZA, Elizeu Clementino. Memórias e trajetórias de escolarização: abordagem experiencial e formação de professores para as séries iniciais do ensino fundamental. In: REUNIÃO ANUAL DA ANPED, 27. Anais. Caxambu: 2004, p. 01-15. CD-ROM. 